\title{
The Impact of National Lockdown as a Response to Covid-19 on Migrated Children: Evidence from Durban, South Africa
}

\author{
Aden Dejene Tolla and Shanta B. Singh ${ }^{*}$
}

\author{
Discipline of Criminology and Forensics Studies, School of Applied Human Science, University of KwaZulu- \\ Natal, South Africa
}

\begin{abstract}
The Novel Coronavirus-2019 (COVID-19) has affected many countries from the beginning of 2020 as it began to spread across the globe. The response of most affected nations was to declare national lockdowns in varying severities. South Africa declared one of, if not the most, severe lockdown of all countries which was termed in the media as "hard lockdown". This paper discusses the COVID-19 pandemic in South Africa and the effects of the national lockdown on children, more specifically children from migrated parents that have settled in South Africa. The research adopted a qualitative approach, coupled with a review of published literature from March-September 14, 2020, to develop an understanding of the effects of the national lockdown on children, from migrated families in Durban. Furthermore, qualitative data was collected through telephonic interviews with10 participants (parents). This paper established that although lockdowns have shown some evidence that they have flattened the curve of the rate of infected persons, it has not gone without any unintended consequences. One of them being its impact on the children of migrated parents. It postulates that lockdown measures may unintentionally cause harm to children both socio-economically, psychologically and in some cases abuse. The researcher recommended that radio and television broadcasting options for primary and secondary school programs.
\end{abstract}

Keyword: Children, COVID-19, Lockdown, Migrated, South Africa.

\section{INTRODUCTION}

In December 2019, a new infectious respiratory disease emerged in Wuhan, Hubei Province, China, and was named by the World Health Organization as COVID-19 which is a Novel Coronavirus (WHO, 2020). In South Africa, the first coronavirus case was announced on March 5, 2020, by Dr Zweli Mkhize the Minister of Health. In response, President Cyril Ramaphosa declared a national state of disaster. The COVID-19 lockdown has affected more than 860 million children and adolescents worldwide, however there is lack of empirical studies to examine the impact on their lives (Mireia Orgiles, Alexandra Morales, Elisa Delvecchio, Claudia Mazzeschi and Jose, Espada, 2020). Novel Coronavirus has affected not only the health sector, but also the world is affected economically, socially, psychologically, emotionally and infection with the virus itself. Children may prove to be the utmost and amongst biggest victims of COVID-19 lockdown with multiple side-effects.

This paper explores the effects of lockdown on children, more specifically children from migrated parents. The psychological effects of lockdown, gender-based violence during lockdown, educational, emotional, and social effects of lockdown on children is briefly discussed. The paper adopted a qualitative research approach, coupled with systematically

*Address correspondence to this author at the Discipline of Criminology and Forensics Studies, School of Applied Human Science, University of KwaZuluNatal, South Africa; E-mail: Singhsb@ukzn.ac.za reviewed all published literature up to September 14 on interventions to determine the effects on COVID-19 on children, from migrated family evidence from Durban, South Africa.

Noble Coronavirus does not have vaccines, or nor a specific drug are accessible until now, and apparently health institutions and facilities are overburdened everywhere in the world (Ebrahim et al., 2020). Nevertheless, medical results show that children are slightly susceptible to COVID-2019, however they are affected the most by the psychosocial impact of the lockdown (Ritwik Ghosh, Mahua Jana Dubey, Subhankar Chatterjee and Souvik Dubey, 2020). The goal of lockdown was to reduce its impact on society, reduce the strain and reduce the intensity of an outbreak (Nuki, 2020). Mitigation measures of the national lockdown, although implemented with the best of intentions, may have caused unintentional harm to children in the short- and long-term The effects of lockdown are that children observing and suffering violence and abuse in the house. The other problem is that children rely on online platforms for distance learning has also increased their risk of exposure to inappropriate content and online predators. This is a global crisis and for some children, the impact of lockdown will be lifelong and the overall risks for child safety because of the pandemic on children will be the worst. One of the most important measures we can take is to keep manner of these impacts on children and restructure healthcare and social services to better benefit at-risk youth (Health24 Infectious Disease, 2020). 


\section{BRIEF LITERATURE REVIEW}

A pandemic was declared by the World Health Organization (WHO) on 11 March 2020, Novel Coronavirus has become a global crisis, and need emergency before its impacts are felt on the entire world population and the economy. The COVID-19 crisis regrettably has affected various economic and social sectors around the global economy, in particular the African economy is severely suffering because of this pandemic. The aviation, oil and tourism sectors are among those sectors affected by the pandemic (Tralac, 2020). Due to COVID-19, businesses such as bars, grocery stores, malls and restaurants have been shutdown to avoid social contact to minimize disease transmission. The lockdown leads to less activity in these sectors and some parents were suspended from their jobs, which had a direct impact on their children. Children are not unsympathetic to the considerable psychological impact of the COVID-19 lockdown. Impact of lockdown on physical and social isolation alongside high level of parental stress directly affect their children, they are exposed to fears, doubts, stress, and substantial changes to their daily routines (Imran et al., 2020).

Health24 Infectious Disease (2020) stated that children should not be neglected during the midst of a pandemic. Economical contrast will have direct and indirect effect on children such as parents being distressed due to retrenchments, low income and future economic prospects. The economy is hit by COVID-19, and parents are unable to provide to basic needs. Understanding children's emotions and responses is important to properly address their needs during this pandemic. This article highlighted that children's vulnerability, provide an overview of common symptoms of distress in different age groups, and summarise the interventions and resources available to promote child mental health and well-being during these challenging times (Imran et al., 2020). The effects will need policymakers to spare the economy any pain from lockdown (Bivens, 2020).

\section{LONG-TERM IMAPACT OF LOCKDOWN ON CHILDREN}

The eventual devastating side effects of the South African national lockdown on children turning point to ask "on how much time it will take for the pandemic to end?" (United Nation [UN] (2020)). A longer struggle to comprise the virus not only prolongs the pain caused by the pandemic and lockdown but increases the possibility of the pandemic's impact will have prolonged or non-stop effects on children, (United Nation [UN] (2020)). In the studies recently conducted by Save the Children on several countries like United States (US) and European countries are reporting that children are victim of feeling bored, stressed, anxious and fearful due to lockdown. Besides that, they are stressing about falling behind in their education and unable to play outside added to their feelings of anxiety and deprivation (Reliefweb, 2020). With some 2.6 billion people around the world in lockdown, national governments are conducting arguably the largest psychological experiment ever. This will result in a secondary epidemic of burnouts and stress-related absenteeism in the latter half of 2020, World Economic Forum [WEF], 2020).

CNN Health (2020) revealed that lockdown drills can make children traumatised and anxious. Lockdown could impose more psychological drain than the physical sufferings caused by the COVID-19 (Ghosh et al., 2020). These studies have shown that prolonged stress has severe long-term consequences like increased risk of mental disorders, chronic disease, obesity and developing unhealthy habits (Health24 Infectious Disease, 2020). Reliefweb (2020) research revealed that feelings of loneliness, separated from loved ones, stigmatisation, helplessness and fear of being socially excluded, stress and social isolation and absence of outdoor play leads to a higher number of mental health conditions in children, such as depression and anxiety.

"We need to respond now to alleviate the toxic consequences of this lockdown on children "(WEF, 2020). Even individuals who never had previous symptoms of depression or anxiety are frequently reporting depression, panic attacks, nightmares, and agoraphobia to friends and on social media. Apparently terrified by continuous media coverage regarding the virus, even though infection, hospitalization and death data suggest the coronavirus have a low risk to them (Real Clear Politics, 2020).

\section{CHILDRENS' PSYCHOLOGICAL WELLING DURING LOCKDOWN}

Children at risk of lasting psychological distress from coronavirus lockdown. "Almost one in four children living under COVID-19 lockdowns, social restrictions and school closures are dealing with feelings of anxiety, with many at risk of lasting psychological distress, including depression" (Reliefweb, 2020). In recent surveys by Save the Children of over 6000 children and parents in the US, 
Germany, Finland, Spain, and the United Kingdom up to 65 percent of the children struggled with boredom and feelings of isolation (Reliefweb, 2020). Closure of school, absence of outdoor activity, abnormal daily life routine including dietary and sleeping habits are like to disorder children's usual lifestyle and then can potentially exposed them to impatience, stress, annoyance and varied neuropsychiatric manifestations (Ghosh et al., 2020).

The mental toll of Coronavirus lockdowns on families and children, the mental toll of lockdowns is to be growing as many states enter their seventh week of mandatory stay-at-home orders (Real clear politics, 2020). A person who stays indoor could have developed the negative feelings and desperation than the person who mostly outside for different reasons. "This is one of the reasons children can slide into negative feelings or even depression during the circumstances they are on lockdown" (Reliefweb, 2020).

\section{GENDER BASED VIOLENCE DURING LOCKDOWN}

Stay home and stay safe is not always applicable for everyone, COVID-19 lockdown strategies have created more challenges more especially for women and children. Reports of child abuse, exploitation, neglect, and domestic violence are on terrible rise during COVID-19 lockdown. Incidences of genderbased violence, domestic violence, child abuse, adulterated online contents are on the rise (Ghosh et al., 2020). Lockdown regulations have created an opportunity to gender based violence and increase the violence against children in South Africa due to lockdown measures. The economic recession, depression, anxiety and violence will increase, that will be observed and internalising the struggle, challenges and stress of their parents. Due to lockdown children childhood physical growth and mental development might be affected, as developmental matters children will be easily missed during this time and will have a long-term impact on children's futures (Health24 Infectious Disease, 2020).

Lockdown caused an increase in Gender Based Violence because it "effectively made it easier for perpetrators to torment their victims with little or no room for support services" (Tanya Farber, 2020). The COVID-19 emergency and social distancing regulations have caused deep apprehensions regarding Gender Based Violence. Several editorials in the South African media have pointed to the increased risk women in these relationships face under lockdown restrictions.
The fear is that they are trapped inside with their abusers, unable to leave, escape or reach out for help (loL, 2020). When the country moved into lockdown mode, logged cases of gender-based violence and domestic abuse in police stations across the country increased dramatically. Some of the victims were eventually killed by their abusers while others were left with physical and emotional scars (Farber, 2020). Moreover, on the matter of hot spots, President Ramaphosa said his Cabinet's mitigation plan against the violence and its perpetrators includes the roll-out of an integrated and multidisciplinary model that incorporates psycho-social support, case investigation, housing services and economic empowerment for survivors under one roof (Farber, 2020). COVID-19 has become a piercing issue and its numerous negative impacts on public health, economy, lifestyle, and wellbeing of populations are challenging policymakers to come up with solutions (ISS, 2020).

Direct and indirect impacts of lockdown on children include the exposure to physical punishment while they are staying at home, aggression and abuse by their parents reduced development of their brain and psyche, higher rates of psychosomatic and neuropsychiatric disorders, multiple substance abuse and suicidal thoughts. Children and teenagers should not be forgotten in mitigation mechanism for the pandemic, as well as being provided with easy-to-access services to address issues besides COVID-19. Furthermore, service providers should also try to be more cognisant of families' home lives when explaining certain protocols (Health 24 Infectious Disease, 2020).

\section{THE IMAPACT OF SCHOOL CLOSURE DUE TO LOCKDOWN}

The COVID-19 pandemic has interrupted everything in the world. Education and schools were amongst the most challenged to provide teaching and learning processes for students due to the lockdown because of the pandemic crisis (Mail online, 2020). Experts understand that the world need to prepare for the worst and prepare best practices that can be followed to diminish the psychological influence of lockdowns on children and their teachers (CNN health, 2020).

Social distancing and lockdown legislation methods could reduce the incidence and duration of social contacts among people of all ages, to decrease person-to-person transmission and infection of the virus. (The BMJ, 2020 The closure of educational institutions (schools and universities), childcare facilities, entertainment venues, religious services, and 
other places where people congregate is an essential measure. Schools and day care centres represent the most socially dense environment compared with offices or homes (The BMJ, 2020). Children online learning opportunity is being used by offenders to communicate with children online. Lockdown legislations and online platforms has opened opportunities for more cybercrimes and expose children that are vulnerable to criminals which take advantage of suppressed cyber security. "Child-abuse materials" seeking activity is on the rise as children are expected to be more vulnerable, having more online exposure and less managed where parents are inattentive, children easily targeted by criminals (Ghosh et al. 2020).

During lockdown, some schools have been implemented some form of distance learning, with providing teaching materials through online portals such as Google Classroom or holding lessons over Zoom or YouTube. However, the implication for distance learning as a direct replacement for face to face learning at school is diverse. Children who are from financially poor backgrounds are often the disadvantaged group and the worst affected by this pandemic, which could be a reason for the stress and mental health impacts of lockdowns (Walls, 2020). Children are extremely discouraged with the sudden shutdown of schooling, home-quarantine, cancellation of scheduled trips and fear of uncertainty concerning the ongoing pandemic. Although the graph of formal education is showing a downtrend, children will hopefully emerge from this misery with pliability, unmatched leniency, solicitude, and cognizance (Ghosh et al. 2020).

An investigation performed among parents has reported that, during the nationwide lockdown children were more exposed to increased screen exposure, movies, and agitation. Children are playing freely and spending excessive time online without any restriction, due to a lonely and humdrum daily routine. As most of the online social network companies have shifted their in-office employees to 'work from home' mode, the regulation and review of potentially harmful contents have gone automated from manual. This automated content moderation has multidimensional fallacies, and the resultant response may be late or inapt (Ghosh et al., 2020). While children might get back on normal educational system, their capacity to learn and catching up is not the same where they are at academically before and can observe a changed academic pathway that may have lifetime implications (Walls 2020). In addition to all of this vulnerability, while children and teachers go back to school with different levels of trauma and stress, who have been exposed to any violence in their homes or communities may relive these experiences during lockdowns (CNN health, 2020).

\section{CHILDREN FROM MIGRATED PARENTS}

Uneven effects of lockdown have affected the whole world. Marginalized societies including migrants, prisoners, homeless are deeply affected by COVID-19 pandemic and researchers indicated that their specific needs to be addressed by the nation (Ghosh et al. 2020). This leaves children and youth who are already at risk such as those living in challenging home environments or children who are lacking social support or whose families are already facing poverty especially vulnerable (Reliefweb, 2020).

Millions of children living in incarceration facilities, immigrant's camps and orphanages, the place where lack liberty and high-density population and transmission of virus (Ghosh et al. 2020). Besides that, the effects of protracted school closure, a sedentary lifestyle, sudden changes in their daily routine already threatens the mental health of children (Children of frontline COVID-19 warriors).

Several millions of refugees, asylum seekers and internally displaced people with their children are confined in overcrowded camps, informal reception stays, and squatter centres with no arrangement for safe drinking water, sanitation barriers, food, and medical services. (Ghosh et al., 2020). They are not receiving adequate health care, appropriate treatment and internet facility making them even easier prey for COVID-19. (Ghosh et al. 2020). Child caring authorities of several countries of the world are defying legal orders and refusing to provide refuge for unaccompanied migrant children despite impending lethal likelihood of COVID-19. Nothing can be worse than the fate of these helpless children who will ultimately be soft targets for criminal minds, human trafficking, exploitation, and all other ill destiny (Ghosh et al., 2020).

\section{THE SOCIO-ECONOMIC EFFECTS OF LOCKDOWN ON MIGRANTS' CHILDREN}

For children caught at the apex of this crisis, there is a genuine prospect that its effects will permanently alter their lives. Children facing acute deprivation in nutrition, protection or stimulation, or periods of prolonged exposure to toxic stress, during the critical 
window of early childhood development are likely to develop lifelong challenges as their neurological development is impaired. Not only anxieties over health, but also for finance and future are the stresses due to lockdown (Ghosh et al., 2020). Children who drop out of school will face not only a higher risk of child marriage, child labour, and teenage pregnancies, but will see their lifetime earnings potential precipitously fall (UN, 2020). Even though children have not been the face of this pandemic as they have largely been spared of the direct health effects of COVID-19 so far, findings of the study indicate that they have been among its biggest victims with multiple side-effects on their physical and psycho-social wellbeing (Hindustan Times, 2020). The gap between those people who are terrified and those with a more complete understanding of the risks of the coronavirus increases, even relationships within families are coming under increasing pressure.

\section{QUALITIATIVE RESEARCH IN DURBAN, SOUTH AFRICA}

The paper adopted a qualitative research approach, coupled with a systematic review of all published literature from March to September 2020, on interventions to determine the effects on COVID-19 on children from migrated families in Durban, South Africa. Participants were selected from the general community. The researchers used the purposive sampling method. To achieve the objectives and research questions of this study, data was collected through telephonic interviews, where 10 participants (all parents) were selected to conduct this research. Six participants were selected though Ethiopian Orthodox Church chief person, Durban. The other four participants are from Zimbabwe. The Ethiopian Orthodox Church Chief person provided the list of six Ethiopians and Eritreans parents' names and their contact numbers. The researcher phoned and contacted to collect the information from participants. The information was translated and transcribed during thematic analysis process for the identification of themes.

The Participants and Procedure telephonic survey which involved migrated parents from Ethiopia and Eritrea were conducted from September 10th September 14th, 2020. Inclusion criteria were: (a) being at least 18 years old, (b) having children and (c) being migrant or a foreigner in South Africa. After the respondents had provided informed consent, they responded to some general questions concerning socio-demographic characteristics including gender, age, education, and employment, as well as some questions related to the effects of lockdown, where they obtain information side effects of the lockdown on their children, if their child have developed different emotions and behaviours during lockdown. They were asked how they managed to follow up and assist online platforms for distance learning and oppositely if the parents experience the positive side of lockdown in Durban, South Africa.

\section{RESULTS AND DISCUSSIONS}

The objective of this research paper was to determine the side effects of the lockdown legislation on children in Durban, South Africa, specific attention given to migrants' (foreigners) children, whom their parents settled in Durban for various opportunities. The participants have been assigned pseudonyms in order to ensure their confidentiality and anonymity.

\section{Psychological Effects of the Lockdown on Children}

The results of this paper revealed that, most of the parents said that lockdown had negative effects on their children. Parents expressed that they observed changes in their children's behaviour and emotional state during the lockdown. Likewise, Reliefweb (2020) research revealed that feelings of loneliness, being separated from loved ones, stigmatisation, helplessness and fear of being socially excluded, stress and social isolation, absence of outdoor play leads to a higher number of mental health conditions in children, such as depression and anxiety.

As one of the participants (P1) explained that "six months is a long period of time to be indoors for a child and children were forbidden to meet or/and play with their friends, unable to go to school or not allowed to go outside anywhere, and that was so difficult to handle and cope with the situation. So, it is understandable if the behaviour and their state is changed. The parent should have understood that". The most frequent behavioural patterns displayed by the children included boredom, feeling of loneliness, worried and uneasiness. Lockdown directly affect their children, they are exposed to fears, doubts, stress, and substantial changes to their daily routines.

\section{Effects of Gender-Based Violence on Children during Lockdown}

According to all participants, they are fully aware of what gender based violence is and the issue is more 
affected women's not children in the migrated community in Durban, South Africa, in fact they have enjoyed their stay with their children, P 3 said that, lockdown have a positive impact as well, regarding with giving opportunities to parents to have more time with their children.

she also said that "as the parent it's difficult to abuse a child and we migrated parents are willing to do anything for our children, actually we are here in South Africa to seek a better life for our children and violence on children have no room for us".

Regarding punishment. P4 emphasized that however it is obvious children must be punished properly when they do something wrong to let them know what they did is not correct. The punishment could be physical or emotional and when spend time together parents might observe mistakes of their children. The direct and indirect impacts of lockdown on children, exposure of the children to physical punishment while they are staying at home, aggression, and emotional abuse by their parents. Long-term home isolation due to lockdown measures to prevent the spread of the COVID-19 outbreak bears the potential for increased risk of gender-based violence in children, like additional challenge of this pandemic.

\section{Social Effects of the Lockdown on Children}

P2 said that "for Ethiopians and Eritreans community, engagement, seeing each other and having a tile togther is a meaningful thing within their society. However, due to lockdown children were not able to engage or meet with their friends, children were not able to take fresh air on time based, we was so scared to take out our children for fresh air and which was difficult situation and affected the children badly, for our community living together, playing, sharing and servicing churches is a meaningful thing and it's our ways of life, lockdown affected us and our children physically, psychologically, emotionally, socially and more importantly their education". While children might get back on normal educational system, their capacity to learn and catching up is not the same where they are at academically before and can observe a changed academic pathway that may have lifetime implications (Walls 2020).

A significant number of respondents believed that news on national media, Facebook and other social media platforms informing the society about the statistics of COVID-19 in South Africa, such as how many people had been infected by the virus, how many had been hospitalized, and how many had died on a day basis had a negative impact on the children's mental wellbeing and were thus uncomfortable to allow the children to follow on these news.

A respondent P6 said that "the news made the children to be more terrified, have nightmares, and caused them to panic more about the virus and the pandemic faced by the world".

An investigation performed among parents has reported that, "during the nationwide lockdown children were more exposed to increased screen exposure, movies, and agitation. Children are playing freely and excessive time online without any restriction, with loneliness and a humdrum daily routine". As most of the online social network companies have shifted their in-office employees to 'work from home' mode, the regulation and review of potentially harmful contents have gone automated from manual. This automated content moderation has multidimensional fallacies, and the resultant response may be late or inapt (Ghosh et al. 2020). Even individuals who never had previous symptoms of depression or anxiety were frequently reporting depression, panic attacks, nightmares, and agoraphobia to friends and on social media (Real Clear Politics, 2020). Terrified by continuous media coverage regarding the virus, even though infection, hospitalisation and death data suggest the coronavirus has a low risk to them (Real Clear Politics, 2020).

\section{Educational Effects of the Lockdown on Children}

During lockdown, some schools have been implemented some form of distance learning, with providing teaching materials through online portals such as Google Classroom or holding lessons over Zoom or You tube (Walls, 2020). Children are extremely discouraged with sudden shutdown of schooling, home-quarantine, cancellation of scheduled trips, and fear of uncertainty concerning the ongoing pandemic (Ghosh et al. 2020).

From the participants, P7 said that: "Even we parents wanted to receive guidance and assistance to understand the online teaching platforms, since we do not have any information and previous background about it. So, our children were lost". Interpretation is that the parents were not capable to assist their 
children and the children were the one doing their follow-up of the classes and duties every week by themselves." Online learning exposed children to unnecessary sites and movies which could expose children to online predators, which can increase the incidence of child trafficking and child porn.

Respondents $\mathrm{p} 8$ from this study stated that "their children's exposure to screens highly increased during the lockdown. she always wanted to assist her children with online learning, the issue was she is not familiar with the system". More than half of the parents reported that children were sad, worried, panicked, feeling scared, feeling of helplessness and loneliness. almost all parents said that children were worried they would not be able to finish their school year. Therefore, children were so frustrated about failing and could finishing the academic year were also children reason to be sad and depressed. Besides that, they are stressing about being falling behind in their education and unable to play outside added to their feelings of anxiety and deprivation.

Some schools had online learning section, however most children were not used to the online program and beside some students were not getting the access because of poor internet access or connectivity and parents cannot provide the computer and all material that enable the child to access the online platform programs. Furthermore, even the parents were not able to home school their children, the system was new for their parents as well. The online learning platforms also created opportunities for perpetrators such as child traffickers and sex offenders to communicate with them online. Lockdown legislations and online platform has opened opportunities for more cybercrimes, has exposed and made children vulnerable for criminals to take advantage of suppressed cyber security. As per (Ghosh et al. 2020) result "Child-abuse materials" seeking activity is on the rise as children are expected to be more vulnerable, having more online exposure and less managed since its working from home mode, children easily targeted by criminals.

\section{The Long-Term Effects of the Lockdown on Children}

Long-term home isolation due to lockdown measures to prevent the spread of the COVID-19 outbreak with huge challenge is that the pandemic hit not only the health system but the economic sector as well. In Durban, South Africa, parents reported that all children were worried about the current pandemic, worried their mother, father or relative might fall sick and falling ill with the virus. Overall, this data indicates that, almost all respondents said that children spent less time doing physical activity or physical exercise, nor reading but they slept more hours during the lockdown and stress.

Another participant also attested to that "the lockdown impacted on the children emotionally and further caused behavioural problems, stress, abnormal eating and sleeping, abnormal life in overall and they disliked being in doors on a 24 hour - 7 days a week basis" (p9).

In South Africa, the economical poor society depend on child support grant but all migrants participated on this research paper does not have a permanent job or does not have support from the South African government financially for their children due to pandemic, so parents were so stressed on the current and future of economic devastation. Furthermore, when family coexistence during lockdown became more difficult, the conditions were very challenging, and the level of tension was higher due to economic devastation. Parents have a tendency to report more economical and emotional difficulties due to economic situations of lockdown and that affected children directly and indirectly. The goal of lockdown is to reduce its impact on society, reduce the strain and reduce the intensity of an outbreak (Nuki, 2020). Health24 Infectious Disease (2020) reveals that children should not be forgotten in pandemic issues; economical contrast will have direct and indirect effect on children. The economy is hit by COVID-19, and the parent unable to provide with basic needs. The COVID19 crisis is affecting the entire world economy, African economy are suffering because of the pandemic, air transport, the oil sector and tourism are impacted (Tralac, 2020).

Almost all participated parents reported that there were higher levels of stress and their children were struggling with fear, stress, torture, and anxiety about their family's situation. Due to COVID-19, the businesses such as bars, grocery stores, malls and restaurants has been shutdown to avoid social contact to minimize disease transmission, the lockdown leads to less activity in these sectors and some parents has been suspended from their job, which will affect their children directly. The effects will need policymakers to spare the economy any pain from lockdown (Bivens, 2020). The marginalised societies including migrants, 
prisoners and homeless are deeply affected by COVID19 pandemic and their specific needs to be addressed by the nation (Ghosh et al., 2020).

In addition to all this vulnerability, while children and teachers back to school with different levels of trauma and stress, who have been exposed to any violence in their homes or communities may relive these experiences during lockdowns (CNN health, 2020). A longer struggle to comprise the virus not only prolongs the pain caused by the pandemic and lockdown but increases the possibility of the pandemic's impact will have prolonged or continued effects on children (UN, 2020). As for children, extended school closure might interfere with healthy habits, regarding outdoor activity and daylight exposure, diet, sleep, and with psychological equilibrium due to boredom, lack of direct information about the disease outbreak, and total absence of in-person relationships with peers.

\section{CONCLUSION AND RECOMMENDATIONS}

The Nobel Coronavirus scourge has challenged the world's health systems and presented multiple effects worldwide. Most nations in the world are affected economically, socially, psychologically, emotionally and infection with the virus itself. South Africa has been affected by the pandemic, and in response, the government has set up an array of measures, including a national lockdown, to reduce the rate of transmission. The paper revealed that children from migrated parents are affected due to coronavirus and South African national lockdown and mitigation mechanism for the pandemic in general. Children from migrated parents are the utmost and amongst biggest victims of coronavirus lockdown with multiple side-effects.

Although lockdowns have shown some evidence that they have flattened the curve of the rate of infected persons, it has not gone without any unintended consequences. One of them being, and the focus of this paper, its' impact on the children of migrated parents'. Children are suffering psychologically and 24 hour - 7 days a week in the home which could escalate to depression and other mental health concerns. The lockdown measures that South Africa has put into place to contain the Novel Coronavirus have negative implications, social distancing and self-isolation led to a reduced workforce across all economic sectors and caused many jobs to be lost. Migrated family shops have closed, and the need for commodities and manufactured products has decreased. The COVID-19 crisis is affecting the entire world economy, migrated parents have more economical and emotional difficulties due to economic situations of lockdown and that affected children directly and indirectly. children should not be forgotten in pandemic issues since economical contrast will have direct and indirect effect on children.

Generally, the socio-economic effects of COVID-19 on individual aspects of the world economy. The parent's stresses on the socio-economy of COVID-19 on their economy have a direct effect on children. The reliance of e-learning by children to continue their education by using online platforms, has increased their risk of exposure to inappropriate content and online predators.

It is recommended that the Government should also plan special programs for migrated families, including not only psychological support but specific projects to sustain families with working parents in ameliorating the impact on children caused by the national lockdown. Specific recommendations directed at children of parents to not discuss adult issues in front of children that will have any negative effect on children, beside to teach them how to take a measure in advance or precaution to prevent the infection. For those parents who cannot providing internet, computer and assist their children on e-learning, the researcher strongly recommended that radio and television broadcasting options for primary and secondary level programs.

\section{REFERENCE LISTS}

Centre for disease control and prevention, 2020. An Approach for Monitoring and Evaluating Community Mitigation Strategies for COVID-19, 2020. https://www.cdc.gov/coronavirus/2019ncov/php/monitoring-evaluating-community-mitigationstrategies.html (Accessed on September 01, 2020).

Children of frontline COVID-19 warriors: Our observations. Available from: https://www.researchgate.net/publication/341385067 Children_of_frontline_COVID-19

warriors_Our_observations (Accessed on September 12, 2020).

CNN health, 2020. What school threats and lockdowns are doing to a generation of children https://edition.cnn.com/2019/04/19/ health/school-threats-lockdown-effects/index.html (Accessed on September 04, 2020).

European Centre for Disease Prevention and Control. COVID-19. https://qap.ecdc.europa.eu/public/extensions/COVID-19 /COVID-19 .html. Updated 2020. (Accessed on September $11,2020)$

Health24 infectious disease2020. Children could be facing long-term health effects indirectly linked to COVID-19. https://www.health24.com/Medical//nfectiousdiseases/Coronavirus/children-could-be-facing-long-termhealth-effects-indirectly-linked-to-COVID-19 $\quad$-20200706-5. (Accessed on September 11, 2020). 
Hindustan Times, 2020. Children among biggest victims of COVID19 lockdown with multiple side-effects: CRY report https://www.hindustantimes.com/india-news/children-amongbiggest-victims-of-COVID-19 -lockdown-with-multiple-sideeffects-cry-report/story-6seNNglhflnQt6IAVV036K.html. (Accessed on September 10, 2020).

Imran N, Zeshan M, Pervaiz Z, 2020. Mental health considerations for children \& adolescents in COVID-19 Pandemic, 2020. Pak J Med Sci. 2020;36(COVID19-S4). (Accessed on September 14, 2020). https://doi.org/10.12669/pims.36.COVID19-S4.2759

ISS, 2020. Concern about domestic violence during the lockdown has had a positive impact in some provinces, 2020. https://issafrica.org/iss-today/gender-based-violence-duringlockdown-looking-for-answers. (Accessed on September 11, 2020).

Josh Bivens, 2020. Economic Policy and the Coronavirus: How to Mitigate Harm and Plan for the Future A list of considerations for policy makers, 2020. https://www.commondreams.org/ views/2020/03/03/economic-policy-and-coronavirus-howmitigate-harm-and-plan-future. (Accessed on September 09, 2020).

Li J, Yang A, Dou K, Wang L, Zhang M, Lin X. Chinese public's knowledge, perceived severity, and perceived controllability of the COVID-19 and their associations with emotional and behavioural reactions, social participation, and precautionary behaviour: A national survey. BMC Public Health. 2020:. (Accessed on September 09, 2020). https://doi.org/10.1186/s12889-020-09695-1

loL, 2020. Ramaphosa identifies 30 gender-based violence hot spots during lockdown, 2020. https://www.iol.co.za/news/politics/ ramaphosa-identifies-30-gender-based-violence-hot-spotsduring-lockdown-875b9b0e-6b08-465e-bcc1-23922d1383c1. (Accessed on September 08, 2020).

Mail online 2020. Boys are lagging further behind than girls after six months without school, survey reveals as pupils head back to classes for first time since lockdown https://www.dailymail.co. uk/news/article-8684639/Lockdowns-legacy-UKs-poorestchildren-Richer-pupils-46-ahead-worse-peers.html. (Accessed on September 09, 2020).

Mireia Orgiles, Alexandra Morales, Elisa Delvecchio, Claudia Mazzeschi and Jose P. Espada, 2020.Immediate psychological effects of the COVID-19 quarantine in youth from Italy and Spain, 2020. (Accessed on September 21, 2020)

https://doi.org/10.31234/osf.io/qaz9w

Nazish Imran, Muhammad Zeshan and Zainab Pervaiz. Mental health considerations for children \& adolescents in COVID-19 Pandemic 2020. Pakistan Journal of Medical Sciences Online 36(COVID19-S4). (Accessed on September 14, 2020).

https://doi.org/10.12669/pjms.36.COVID19-S4.2759

Oliver Frankiln-Walls 2020. Wired UK, 2020. Shutdowns Have LongTerm Effects on Children. https://www.wired.com/story/howschool-shutdowns-have-longterm-effects-on-children/. (Accessed on September 17, 2020).

Real clear politics, 2020. The Mental Toll of Coronavirus Lockdowns on Families \& Children. https://www.realclearpolitics.com/ articles/2020/05/06/the_mental_toll_of_coronavirus_lockdow ns on families children 143132.html\#!. (Accessed on September 10, 2020).

Reliefweb, 2020. 'Children at risk of lasting psychological distress from coronavirus lockdown': Save the Children. https://reliefweb.int/report/world/children-risk-lastingpsychological-distress-coronavirus-lockdown-save-children (Accessed on September 09, 2020).

Ritwik Ghosh, Mahua Jana Dubey, Subhankar Chatterjee and Souvik Dubey, 2020. Impact of COVID-19 on children: Special focus on psychosocial aspect, 2020. https://www.researchgate.net/ publication/341214452_Impact_of_COVID-19 on children Special focus on psychosocial aspect Minerva Pediatrica 72(3):226-235. (Accessed on September 10, 2020). https://doi.org/10.23736/S0026-4946.20.05887-9

Tanya Farber, 2020. Shocking stats on gender-based violence during lockdown revealed,2020 https://www.timeslive.co.za/news/ south-africa/2020-09-01-shocking-stats-on-gender-basedviolence-during-lockdown-revealed/. (Accessed on September 18, 2020).

The BMJ, 2020. COVID-19 and community mitigation strategies in a pandemic BMJ 2020; 368 doi: https://doi.org/10.1136/ bmj.m1066 (Published 17 March 2020) Cite this as: BMJ 2020;368:m1066 https://www.bmj.com/content/368/ bmj.m1066. (Accessed on September 16, 2020).

The Dan Bangino show, 2020 As Unbiased America reports, 2020 https://bongino.com/study-global-lockdowns-killing-10000children-per-month. (Accessed on September 14, 2020).

Tralac, 2020. Impact of the Coronavirus (COVID-19) on the African Economy, 2020. https://www.tralac.org/news/article/14483impact-of-the-coronavirus-COVID-19 -on-the-africaneconomy.html. (Accessed on September 09, 2020).

United Nations Industrial Development Organization https://www.unido.org/stories/coronavirus-economic-impact10-july-2020

Viner RM, Russell SJ, Croker $\mathrm{H}$, et al. School closure and management practices during coronavirus outbreaks including COVID-19: A rapid systematic review. Lancet Child Adolesc Health. 2020. (Accessed on September 13, 2020). https://doi.org/10.1016/S2352-4642(20)30095-X

Wang C, Pan R, Wan X, et al. Immediate psychological responses, and associated factors during the initial stage of the 2019 coronavirus disease (COVID-19) epidemic among the general population in china. Int J Environ Res Public Health. 2020;17(5):1729. (Accessed on September 15, 2020). https://doi.org/10.3390/ijerph17051729

World Economic Forum, 2020. Lockdown is the world's biggest psychological experiment - and we will pay the price, 2020. https://www.weforum.org/agenda/2020/04/this-is-thepsychological-side-of-the-COVID-19 -pandemic-that-wereignoring/. (Accessed on September 14, 2020).

World Health Organization (WHO). WHO director-general's opening remarks at the media briefing on COVID-19 - 11 March 2020. https://www.who.int/dg/speeches/detail/whodirector-generals-opening-remarks-at-the-media-briefing-on-COVID-19 ---11march-2020. Updated 2020. (Accessed on September 19, 2020).

Received on 01-08-2021

Accepted on 14-09-2021

Published on 21-10-2021

https://doi.org/10.6000/1929-4409.2021.10.160

() 2021 Tolla and Singh; Licensee Lifescience Global.

This is an open access article licensed under the terms of the Creative Commons Attribution License (http://creativecommons.org/licenses/by/4.0/) which permits unrestricted use, distribution and reproduction in any medium, provided the work is properly cited. 